\title{
Les frontières de l'Éternité ? Le cas d'un nom de monnaie : santalene
}

\begin{abstract}
Resumé - Ce texte examine le mot santalene qu'on trouve dans des sources italiennes médievales et propose de l'identifier avec des monnaies byzantines sur lesquelles la dévotion médiévale croyait voir les images de Constantin et de sainte Hélène, ou de l'un d'entre eux, dans le contexte du culte de la Vraie Croix. Cette interprétation repose sur le témoignage de trois trésors italiens des $\mathrm{XI}^{\mathrm{e}}, \mathrm{XII}^{\mathrm{e}}$ et $\mathrm{XIII}^{\mathrm{e}}$ siècles et sur le cas de plusieurs autres monnaies byzantines conservées en Italie comme objets de dévotion : quelques-unes d'entre elles proviennent du trésor retrouvé au Latran en 1586, dont les monnaies furent dotées d'indulgences par une bulle papale de Sixte Quint de 1587. Le culte de la Vraie Croix fut assez répandu dans l'Europe médiévale et on suggère qu'en France aussi des monnaies « de sainte Helène », romaines ou byzantines, furent considérées comme objets de dévotion.
\end{abstract}

Summary -This paper deals with the interpretation of the name santalene mentioned by some medieval Italian documents; the author proposes to identify the term with Byzantine coins whose iconography was read by medieval piety as images of Constantine and saint Helen, or one of them, in the context of the cult of the True Cross. This devotional interpretation is based on three medieval Italian hoards and on several other Byzantine coins preserved in Italy as objects of devotion, some of which belonged to the Lateran hoard of 1586: a hoard which inspired a papal bull of indulgences issued by pope Sixtus V in 1587, according to which each specimen was to become a sort of relic. The cult of the True Cross was very popular in medieval Europe and it is suggested that in France too coins 'of saint Helen', whether Roman or Byzantine, were also considered as objects of devotion.

Ce texte est dédié à Françoise Dumas qui a traité dans ses études de quasiment tous les sujets de la recherche numismatique : elle s'est interessée aussi aux noms des monnaies dans les sources écrites médiévales, et ici je voudrais examiner les differentes interprétations du terme de santalene. Le titre énigmatique de cet article, qui s'éclairera au fil de l'exposé, est lié à l'interprétation dévotionnelle de ces pièces en relation avec culte de la Vraie Croix.

Le nom de santalene avait attiré mon attention pour la première fois quand j'étais à Cambridge et pouvais me plonger dans les archives de notre maître Philip Grierson et en particulier dans son dossier intitulé 'Coin valuations' qui contenait des listes de monnaies relevées dans diverses « pratiche di mercatura » (manuels de marchandise) et dans des livres de mathématique de la période comprise entre les années 1280 et $1450^{1}$.

* Professeur à l'Université de Milan, Università degli Studi di Milano, Dipartimento di Scienze dell'Antichità, Via Festa del Perdono 7, 20122 Milano. Courriel : ltravai@tin.it.

1. Ce dossier fut le point de départ du livre de Lucia Travain, Monete, mercanti e matematica. Le monete medievali nei trattati di aritmetica e nei libri di mercatura, Rome, 2003. 
Les santalene d'or se trouvent mentionnées seulement dans les listes les plus anciennes, de 1280 environ à 1315 au plus tard.

a) Sante alene vechie sono a charati 24 meno 1/3 (Columbia University, Ms X511 Al 3 : liste de 1280 environ) ${ }^{2}$;

b) Santalene fini sono a kar. 24 per oncia (Jacopo da Firenze, Tractatus algorismi : liste de 1302 environ);

c) santa'alene d'oro vecchie XXIIII meno $1 / 4$ (Venise, Bibl. Marciana, Cod. ital. Cl.XI, n. 98 : liste datée de 1305);

d) sant'alene d'oro col taglio grosso a ka. XXIII e 1/4 (Florence, BN, Racc. Tordi n.139, Cod. Acciajoli, liste de 1311-1315 environ).

Il n'existe pas d'atelier monétaire qui puisse être identifié comme l'origine du mot santalena, ni de monnaies avec la représentation de sainte Hélène. Mais les listes des manuels de marchandise enregistrent toujours des monnaies qui étaient certainement connues des marchands et changeurs de l'époque et qui pouvaient se trouver dans leur mains. Les contenus de fin indiqués ici sont presque celui de l'or fin. De quelles monnaies alors peut-il s'agir?

J'ai tenté d'imaginer quel type de monnaie pouvait être interprété comme une représentation de sainte Hélène et j'ai revisité trois trésors italiens médiévaux qui me paraissaient pouvoir fournir la réponse :

1 - Ordona, enfoui vers 1030 : 147 taris de Salerne et Amalfi et 1 histaménon de Basile II et Constantin VIII (976-1025) ;

2 - Rome, Torre delle Milizie, enfoui vers 1185 : 1370 deniers de Champagne, Lucques, Pavie, et 1 histaménon de Basile II et Constantin VIII ;

3 - Pise, Logge dei Banchi, enfoui vers 1266 : 119 taris de Sicile, 16 augustales et 1 demi augustalis de Frederic II, 1 grosso d'or de Lucques, 91 florins de Florence, et 1 histaménon de Basile II et Constantin VIII.

Dans les trois cas les histaména d'or sont du même type, c'est-à-dire la classe 6 de $D O C$, avec une croix latine entre les bustes des deux empereurs et deux croissants dans le nimbe du Christ. Ce type est le plus commun du règne, mais aussi le seul qui puisse se rapporter à la croix de Jésus-Christ : le buste de Basile II pouvait alors être interprété par des Italiens du Moyen Âge comme le buste de Constantin le Grand et le buste du jeune Constantin VIII, imberbe, comme le buste de sainte Hélène ${ }^{3}$. Si on imagine qu'ils aient pu être thésaurisés

2. Les transcriptions des listes citée ici sont d'après TRAVAINI, op. cit. n. 1, passim. Le manuscrit du traité arithmétique de l'Université Columbia est datable du milieu du XIV siècle mais la liste de monnaies est sans aucun doute antérieure, datant de 1280 environ (TravainI, op. cit. n.1, p. 82). Sur la base de cette datation plus haute Jens Høyrup a proposé de dater le texte entier de 1280 environ, ce qui en ferait le plus ancien texte d'algorisme en italien vulgaire : J. HøYruP, Leonardo Fibonacci and abbaco culture. A proposal to invert the roles, Revue d'histoire des mathématiques, 11, 2005, p. 23-56.

3. Les santalene seraient des monnaies d'or byzantines des environs de l'an 1000 selon E. Martinori, La moneta. Vocabolario generale, Rome, 1915, p. 447. 
comme des médailles de piété, on pourrait mieux justifier la présence systématique d'un seul exemplaire dans chacun des trois trésors. J'ai proposé pour la première fois cette interprétation dévotionnelle lors d'un colloque à Dumbarton Oaks organisé en l'honneur de Philip Grierson ${ }^{4}$. Elle me semble plus satisfaisante que celle que j'avais proposée auparavant dans mon livre sur le monnayage de l'Italie normande en 1995, où j'interprétais cette présence comme le cas d'une thésaurisation prolongée de ce type byzantin antérieur à la dévaluation ${ }^{5}$ (une interprétation qui laissait inexpliqué le fait qu'il y avait toujours un exemplaire seulement dans chaque trésor). Je crois davantage à la possibilité que ces monnaies aient été conservées et soient passées de père en fils pour leur valeur iconographique, comme des icônes dans le contexte du culte de la Vraie Croix et de celui de Constantin et Hélène. Ce culte était par ailleurs bien diffusé dans le monde byzantin, si on pense par exemple aux monnaies appelée konstantinata, qui, selon la lettre de Michel Italikos (milieu du XII ${ }^{\mathrm{e}}$ siècle), montraient sur un côté l'image des « très pieux » Constantin et Hélène et sur l'autre côté celle du Christ « de type romain $»^{6}$.

Bien naturellement je n'ai pas convaincu tout le monde et j'ai reçu quelques observations critiques importantes. Des collègues ont observé que dans le Convivio Dante fait référence aux santalene d'argent qu'il considérait avoir deux mille ans ${ }^{7}$; les santalene seraient alors des monnaies antiques, probablement

4. L. Travaini, The Normans between Byzantium et the Islamic World, Dumbarton Oaks Papers, 55, 2001, p. 179-196, avec la bibliographie détaillée sur les trois trésors mentionnés. Après avoir lu cet article, Philip Grierson m'avait signalé un article, que je connaissais pas, très utile pour documenter un lien très fort entre les monnaies «de Constantin » (et Helène) et les monnaies byzantines du $\mathrm{IX}^{\mathrm{e}}$ et du $\mathrm{x}^{\mathrm{e}}$ siècle avec les bustes de deux empereurs : F. W. HasLuck, Constantinata, in Essays and Studies presented to William Ridgeway, G. QuigGin éd., Cambridge, 1913, p. 635-638 (avec l'Addendum suivant : "While this paper was in the press, my attention was called by Mr G. F. Hill to a passage in Rev. Num. sér. IV, vol. XII, 1908, p. 137, mentioning an escudeletto di Sto-Eleno (sic) used as charme in Provence: it is described as a "monnaie byzantine scyphate qui préserve des maléfices" »).

5. L. Travaini, La monetazione dell'Italia normanna, Rome, 1995 (Nuovi Studi Storici 28, Istituto Storico Italiano per il Medio Evo), p. 11.

6. Dans ce cas il s'agissait d'une monnaie d'or « vieille » au XII ${ }^{\mathrm{e}}$ siècle, probablement encore une fois une pièce avec deux empereurs associés avec une croix entre eux : pour cette lettre et les problèmes d'interprétation qu'elle pose : Travaini, op. cit. n. 4 ; T. BerTelè, Costantino il Grande e S.Elena su alcune monete bizantine, Numismatica, 14, 1948, p. 91-106 ; C. PerASSI, Un prodigioso filatterio monetale nella Costantinopoli del XII secolo: l'epistola 33 di Michele Italico (con un'appendice di Carlo Maria Mazzucchi), Aevum. Rassegna di Scienze storiche linguistiche e filologiche, LXXIX, 2, 2005, p. 363-405; H. MAGUIRE, Magic and Money in the Early Middle Ages, Speculum, 72, 1997, p. 1037-1054 ; V. LAURENT, Numismatique et folklore dans la tradition byzantine, Cronica Numismatică şi archeologică, 119-120, 1940, p. 250-263.

7. Convivio (IV, XI.8, écrit entre 1304 et 1307) ; «Veramente io vidi lo luogo, ne le coste d'un monte che si chiama Falterona, in Toscana, dove lo più vile villano di tutta la contrada, zappando, più d'uno staio di santalene d'argento finissimo vi trovò, che forse più di dumilia anni l'avevano aspettato ». Pour une tentative d'explication des santalene d'argent voir TravainI (op. cit. n. 4) . 
romaines $^{8}$. Mais il faut ici souligner d'abord que l'ouvrage de Dante est de la littérature, alors que les listes de monnaies médiévales des «pratiche » ou des traités mathématiques donnent des informations précises sur les pièces. Il n'est pas impossible que ces listes attestent la fin de l'existence monétaire de ces pièces d'or byzantines, qui au XIV $V^{\mathrm{e}}$ siècle avaient pris désormais un rôle d'objets de piété, et se trouvaient reproduites aussi par les orfèvres, comme le mentionne par exemple le traité de Cennino Cennini ${ }^{9}$. Les commentaires de Dante ont par ailleurs toujours qualifié les santalene de pièces byzantines. On peut aussi souligner le fait qu'au Trecento les monnaies byzantines étaient aussi des monnaies « romaines » d'un style « ancien».

La question se pose donc dans les termes suivants : les santalene sont-elles des monnaies byzantines (avec une croix certainement ; de Basile II et Constantin VIII au témoignage des trois trésors décrits plus haut) ou des monnaies romaines ? Marc Bompaire m'avait signalé que selon Nicolas-Claude Fabri de Peiresc (1580-1637) les santalene étaient des monnaies romaines ${ }^{10}$ comme le rapporte le livre d'Yves-Marie Bercé, À la découverte des trésors cachés du $X V I^{e}$ siècle à nos jours ${ }^{11}$. Il s'agissait bien de monnaies romaines, mais en réalité le témoignage de Peiresc ne se réfère pas tout simplement à des pièces romaines puisque il nous fait savoir qu'en Provence les trouvailles de pièces romaines, qui n'étaient pas rares, étaient appelées «médailles de sainte Héléne » parce que beaucoup d'entre elles portaient l'effigie de cette impératrice ${ }^{12}$.

Monnaies romaines alors? Le pourcentage des pièces frappées par Constantin pour Hélène n'est pas assez important pour justifier cette interprétation si l'on considère l'ensemble des trouvailles romaines : je crois plutôt qu'il y avait, en Provence au XVI èècle, la volonté d'y voir des images qui n'y figuraient pas ou plutôt qui n'étaient pas exactement celles qui y figuraient (comme dans l'Italie médiévale pour les pièces de Basile II et de Constantin VIII qu'on vient d'examiner). En Provence aussi il y avait, je crois, une interprétation religieuse, comme pour les santalene italiennes. On trouve ici la raison de mon titre « fron-

8. Sur ce phénomène en général voir l'interprétation d'Andrea SACCOCCI, Ritrovamenti di monete islamiche in Italia continentale ed in Sardegna (sec. VII-XV), in Simone Assemani Symposium sulla monetazione islamica. Simone Assemani Symposium on Islamic Coinage, Padova, II Congresso Internazionale di Numismatica e di Storia Monetale. The 2nd International Congress on Numismatic and Monetary History, Padova 17 maggio 2003, (Numismatica Patavina 7), Padoue, 2005, p. 137-149 où il analyse aussi les depôts de fondation : pour un commentaire du sujet voir L. TravainI, La bolla numismatica di Sisto V, i riti di fondazione e due monete reliquie a Milano, Sanctorum, 4, 2007, p. 203-240.

9. C. Cennini, Il libro dell'arte, a cura di Franco Brunello, Vicence, 1993, p, 206-207 : les santalene dans ce 'libro' sont commentées en détail dans L. TRAVAINI (op. cit. n. 8), à la note 41.

10. Je suis reconnaissante à Marc Bompaire de m'avoir signalé ce point. J'ai fait référence à cette interprétation de Peiresc des santalene comme des « monnaies romaines » tout simplement, dans mon article cit. n. 8.

11. Y.-M. Bercé, À la découverte des trésors cachés du XVIe siècle à nos jours, Paris, 2004.

12. BERCÉ, op. cit. n. 11, p. 202 : il ne donne pas la référence précise à Peiresc. 
tières de l'éternité » : y avait-il vraiment une frontière des dévotions à la Croix, ou à Hélène et Constantin? Je crois plutôt que ce culte était assez répandu au Moyen Âge tant à Byzance qu'en Occident et qu'il pouvait s'exprimer de plusieurs façons : en Provence, au moyen des pièces romaines dites «d'Hélène » (en réalité n'importe quelles pièces portant une croix ou un christogramme); en Italie par des pièces byzantines dites santalene (avec une croix d'un type quelconque et, si possible, deux empereurs côte à côte). Je crois qu'il n'y avait pas de frontière pour ce culte : sainte Hélène était, depuis saint Ambroise de Milan, l'inventrice de la vraie Croix de Jésus ${ }^{13}$. La réponse à la question des santalene ne peut se trouver à mon avis que dans les différents contextes des trouvailles monétaires : il faut toujours se contenter de ce qu'on trouve.

Je voudrais maintenant présenter une réponse au problème de santalene qui nous vient de la cour pontificale de Rome au $\mathrm{XvI}^{\mathrm{e}}$ siècle : en l'année 1586 un trésor de 125 monnaies d'or byzantines enfoui au viI ${ }^{\mathrm{e}}$ siècle sous le règne d'Héraclius fut mis au jour pendant l'excavation des fondations du nouveau Palais du Latran à Rome. Il comptait des exemplaires des empereurs Théodose, Valentinien III, Marcien, Léon, Justin, Justinien, Tibère II Constantin, Maurice Tibère, Phocas et Héraclius ${ }^{14}$. Les Avvisi di Roma considéraient toutes ces pièces comme des «monnaies de sainte Hélène » :

"La mattina di san Giovanni il papa donò una di quelle monete di santa Helena per uno alli cardinali che accompagnarono S(ua) B(eatitudine) da Montecavallo a san Giovanni Laterano, ritrovate al numero di 125 in una cassetta di ferro murata in quelle rovine che si gettano a terra per la nuova fabbrica. Dette monete sono d'oro ma di prezzo di 13 giuli l'una solamente"'15.

(Le matin de la Saint-Jean le pape fit don à chacun des cardinaux qui accompagnaient Sa Sainteté de Montecavallo à Saint-Jean-de-Latran d'une de ces monnaies de sainte Hélène qui avaient été trouvées au nombre de 125 dans une cassette en fer murée dans ces ruines que l'on abattait pour la nouvelle construction. Ces monnaies sont en or mais sont estimées seulement à 13 giuli [monnaie d'argent émise par Jules II en 1504] chacune).

13. Lexikon der christlichen Ikonographie, E. Kirschbaum éd., II, Rome, 1970, s.v. Kreuzlegende, col. 642-648.

14. Détails sur le trésor et ses interprétations dans Travaini (op. cit. n. 8). Selon T. R. Volk des exemplaires du trésor du Latran seraient identifiables parmi ceux de la collection de Fulvio Orsini, entrée ensuite dans la collection Farnèse, mais à mon avis la bulle papale de 1587 semble exclure cette possibilité : la bulle en effet donne à chaque pièce du trésor un puissante valeur pour les indulgences qu'elle promet; selon la bulle, de plus, toutes les pièces furent distribuées entre les souverains, les cardinaux et de grands personnages pour en répandre la vénération (quelques résultats des recherches de T. R. Volk sur ce trésor furent présentés au cours du Congrès international de numismatique de Berlin de 1997 mais ne sont pas publiés dans les Proceedings : un résumé parut dans les "Abstracts of Papers" du même congrès : T. R. VolK, The 1586 Lateran Palace hoard, in XII. Internationaler Numismatischer Kongress. Vortragszusammenfassungen, Berlin, 1997, p. 43).

15. R. Lanciani, Storia degli scavi di Roma, IV, Rome, 1912, p. 139-140 (2e ed., Roma 1992, p. 151-153). 

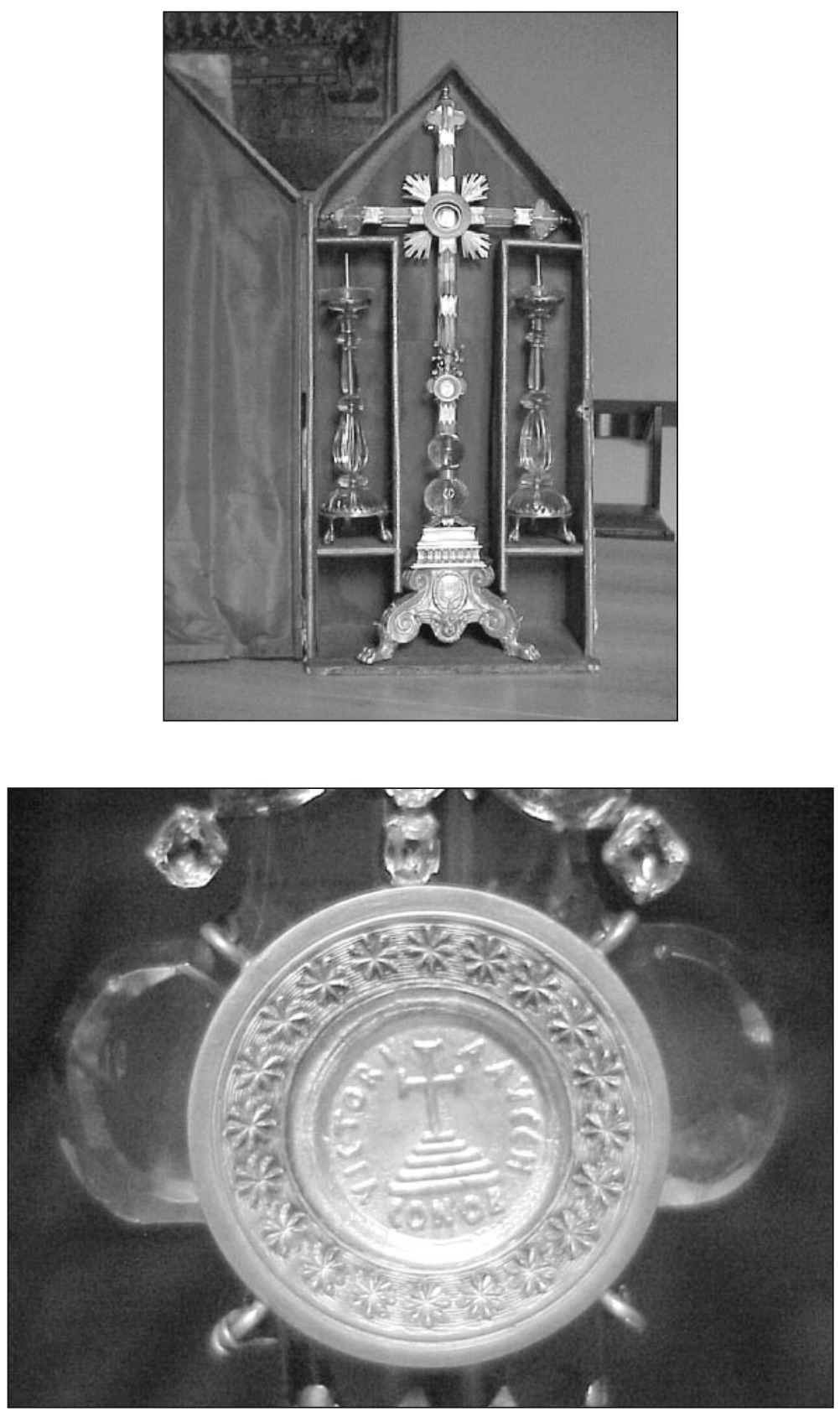

Figures 1 et 2 - Croix en cristal et détail (bas) ; Milan, Église de Sant'Alessandro (Padri Barnabiti Comunità di Sant'Alessandro) 
La composition du trésor nous est décrite par un document extraordinaire : une bulle papale numismatique du $1^{\text {er }}$ décembre 1587 (texte latin en Appendice). ${ }^{16}$

Le pape Sixte Quint (1585-1590) en effet fut très impressionné par cette découverte : il y vit une intervention de Dieu et en arriva à considérer chaque pièce comme une offrande personnelle de la part de ces anciens empereurs envers l'Église romaine - en dépit du fait qu'il s'agissait d'un trésor. Aussi se décida-t-il à citer en exemple ces pieux empereurs romains et byzantins aux souverains de son temps, au moment où l'Église était attaquée par le protestantisme ${ }^{17}$. Les empereurs, dont les monnaies se trouvaient dans le trésor, figurent d'ailleurs sur les fresques du Salon des Empereurs du Palais du Latran, tous agenouillés aux pieds de l'Église romaine ${ }^{18}$.

Le texte entier de la bulle papale est d'un grand intérêt. L'indulgence était accordée à tous ceux qui porteraient sur eux une monnaie de ces empereurs ou aux églises qui en conserveraient une pour ceux qui iraient y prier. Une indulgence était accordée aussi à ceux qui porteraient sur eux une telle pièce au moment de leur mort, y compris en particulier tous ceux qui, soldats ou non, se battraient contre les infidèles, les hérétiques et tout autre ennemi de l'Église de Rome.

Pour diffuser ces pièces le pape en donna à l'empereur, à divers souverains, cardinaux et autres grands personnages, qui, avant leur mort, étaient invités par la bulle à offrir ces pièces aux églises pour y perpétuer la dévotion.

Le cardinal milanais Agostino Cusano avait reçu une de ces pièces ; avant de mourir il la légua à l'église de Sant'Alessandro à Milan, où elle se trouve encore aujourd'hui (figures 1 et 2). Les documents et les guides de la ville du $\mathrm{XVII}^{\mathrm{e}}$ siècle en parlent comme de la « sacra medaglia »du Latran, et y soulignent la présence de l'image de la croix sans jamais employer toutefois le terme santalena ${ }^{19}$.

16. Le texte latin est celui du Bullarium Diplomatum et Privilegiorum sanctorum Romanorum Pontificum Taurinensis editio, VIII, Torino 1863, p. 966-972; une traduction intégrale en italien par le R. P. Don Antonio Cipollaro est publiée dans L. Travain, Monete e storia nell'Italia medievale, Rome, 2007, Appendice 4.

17. Je ne prendrai pas en considération ici tous les problèmes de cette interprétation papale, ni les aspects liés aux monnaies deposés dans les fondations de bâtiments médiévaux (discutés dans TravainI, op. cit. n. 8) : le pape voulait croire qu'il s'agissait en tout cas de monnaies offertes par chacun de ces divers empereurs, dans la fondation de bâtiments consacrés par eux-mêmes sur le site du Latran ; cet usage était par ailleurs très répandu à la Renaissance.

18. On ne sait pas si le pape choisit le sujet de ces fresques après la découverte du trésor mais ce n'est pas impossible.

19. Pour le culte de cette pièce, et d'une autre pièce dite de Justin $\mathrm{I}^{\mathrm{er}}$ - desormais disparue conservée dans l'église voisine de Sant'Antonio, et pour les abus d'un tel culte au XVII ${ }^{\mathrm{e}}$ siècle, voir Travaini, op. cit. n. 8. 
En conclusion, je voudrais souligner les points principaux des mes réflexions :

1 - le mot santalena ne peut que se référer en tout cas à sainte Hélène ;

2 - les listes médiévales des « pratiche di mercatura » et des livres de mathématique désignent probablement sous le nom de santalena le nomisma histaménon de Basile II et Constantin VIII, une monnaie attestée dans trois trésors italiens des $\mathrm{XI}^{\mathrm{e}}-\mathrm{XIII}{ }^{\mathrm{e}}$ siècles et thésaurisée à mon avis comme objet de piété. D'autres témoignages nous portent à voir des santalene dans plusieurs types de pièces byzantines : la collection du Museo Archeologico de Florence - collection des Médicis - est riche d'un grande nombre de pièces d'or byzantines percées (depuis Léon I ${ }^{\mathrm{er}}, 457-474$, jusqu'à Manuel I ${ }^{\mathrm{er}}$ Comnène, 1143-1180) : ce sont toutes des santalene de diverses époques que l'on portait suspendues comme ornement ou talisman ${ }^{20}$;

3 - là où il était plus facile de retrouver des monnaies byzantines, on avait des santalene byzantines ; en Provence - ou ailleurs - l'on se contentait peutêtre de monnaies romaines, de préférence avec une croix ou un christogramme sur le labarum ${ }^{21}$;

4 - à Rome les santalene sont bien documentées par la trouvaille du Latran de 1586 , et encore au XVII ${ }^{\mathrm{e}}$ siècle, malgré le progrès des études numismatiques, on peut observer la persistance de la dévotion à sainte Hélène ; un reliquaire, conservé dans la basilique Saint-Pierre au Vatican, est surmonté par une santalena dite provenir du trésor du Latran - en fait une pièce d'or de Manuel $\mathrm{I}^{\mathrm{er}}$ Comnène : selon la description de Torrigio, le Christ Emmanuel au droit représentait Constantin et l'empereur Manuel au revers, Hélène avec le labarum : donnée par un cardinal, cette pièce ne pouvait pas avoir fait partie des monnaies du Latran... mais le désir d'avoir une pièce d'un tel trésor était évidemment très puissant $^{22}$.

Comme je l'ai déjà dit, Sixte Quint distribua les pièces du trésor du Latran aux cardinaux et aux princes catholiques : c'est maintenant à vous, chère Françoise, et à nos collègues français, d'en trouver des exemplaires en France, dans les listes de trésors ou les reliques des églises.

20. 16 exemplaires sont illustrés dans le catalogue de l'exposition Die Magie des Goldes. Antike Schätze aus Italien, her. W. SEIPEL, Kunsthistorisches Museum Wien 12.11.1996-2.2.1997, Milan, 1996, p. 139-141, n. 192-207 ; parmi les pièces percées figure aussi un tremissis lombard avec la légende +FLAVIA LVCA (n. 208).

21. Il faudrait lire le passage exact de Peiresc cité sans référence par BERCÉ, op. cit. n. 11 ; mais, pour une autre « santalene » en Provence voir aussi HAsLucK, op. cit. n. 4 (son Addendum).

22. F. M. Torrigio, Le sacre grotte vaticane, Rome, $1635^{2}$, p. 246 (in LANCIANI, op. cit. n. 15): «nella sommità di tale reliquiario, fù posta una di quelle monete d'oro (come si dice altrove) trovate nel Laterano sotto Sisto V, qui donata da un Cardinale, e vi si vede l'effigie di Costantino, \& Elena con il Labaro » : plus de détails dans TravainI, op. cit. n. 8, p. 214. 


\section{APPENDICE}

\section{La bulle numismatique de Sixte Quint}

\section{Transcription du Bullarium Diplomatum et Privilegiorum sanctorum Romanorum Pontificum Taurinensis editio, VIII, Turin 1863, p. 966-972.}

CXIV. Indulgentiarum elargitio pro quorumdam christianorum imperatorum numismata gestantibus, aut ecclesias, ubi ea asservantur, visitantibus, et pia opera hic expressa exercentibus.

Sixtus episcopus, servus servorum Dei, ad perpetuam rei memoriam.

Laudamus viros gloriosos, christianos praesertim imperatores, in iis quae, pro christiana religione tuenda et propaganda, pie ac praeclare gesserunt, dum pietatis zelo, virtutis magnitudine et imperii maiestate vere augusti, eiusdem religionis, quam omnibus gentibus omnibusque nationibus Deus voluit apostolicis vocibus praedicari, cultum totis in Christo visceribus amplexi, usque adeo suis quisque temporibus de hac Sacrosancta Sede, cui, auctore Domino, licet immeriti, praesidemus, egregie promereri studuerunt, ut vera et orthodoxa fides, ex apostolico hoc fonte dimanans, tunc eorum ope et patrocinio munita, propulsatis hostium oppugnationibus, toto terrarum orbe diffusa floreret, omnisque lingua confiteretur, quoniam Dominus Iesus Christus in gloria est Dei Patris. Eorum sane ipsorum, quos constituit Dominus propugnatores et defensores Ecclesiae suae, illustria pie recteque factorum exempla, ad omnem gloriam insignia, imitationisque studio dignissima, ac merita praeclara, cum semper pro grati in eos animi testatione et officio commemorare debemus; tum, hoc potissimum tempore, quo nobis eorum memoriam renovandi mirifica divinitus oblata est occasio, id impensius faciendum arbitramur.

1. Nam, cum ab ipso nostri pontificatus initio, ad exornandam novis aedificiis Lateranensem praecipue basilicam, nullis parcentes impensis, animum adiicissemus, effectum est, non obscura divinae voluntatis significatione, ut demoliendis quibusdam aulae Lateranensis pervetustis ac pene collabentibus parietibus, complura antiqua diversis in locis recondita numismata, ex auro purissimo obryzo confecta, invenirentur, in quibus ex una parte salutiferae crucis signum aut imago aliqua eadem cruce insignita cernitur, ex altera vero vultus effigiesque expressae sunt diversorum veterum, qui ante annos circiter mille floruerunt; augustorum imperatorum, nimirum Theodosii senioris, duorum filiorum eius Arcadii et Honorii, necnon Theodosii iunioris, Valentiniani tertii, Marciani, Leonis, Iustini, Iustiniani, Tyberii, Mauritii, Phocae et Heraclii, qui, etsi longo locorum intervallo disiuncti, urbem Romam ne fortasse quidem omnes umquam viderint, Magni tamen Constantini piissimi imperatoris exemplo et munificentia excitati, ad declarandum pietatis suae studium erga gloriosos apostolorum principes et fortissimos Christi martyres, quorum innumerabilis multitudo in hac sancta civitate requiescit, et quorum praesenti ope et auxilio domi forisque votis susceptis saepe numero rempublicam fortiter et feliciter administraverant, et clarissimae de hostibus victorias reportaverant, huius 
almae Urbis sacras basilicas, atque hanc in primis sacrosanctam Lateranensem, donariis et oblationibus quamplurimis, augustali pietate et magnificentia dignis, cumularunt, diversisque aut novorum aedificiorum extructionibus, aut veterum instaurationibus pro temporum varietate ornarunt. Quod cum alia multa antiquitatis monumenta tum vel haec ipsa nuper reperta aurea tot inclytorum imperatorum numismata testantur, religioso plane consilio et occulto quodam Dei instinctu, in his aedificiis reposita, ut post multa saecula aliquando tandem patefacta in lucemque prolata, eorundem imperatorum singularem religionem et perpetuam erga sanctam Romanam Ecclesiam devotionem insigni apud posteros testimonio comprobarent. Qua in re divinam providentiam agnoscimus, suspicimus atque admiramur, quod calamitoso hoc tempore, cum tam multi crucis Christi Domini hostes catholicae fidei veritatem impiissime oppugnant, praedictorum imperatorum effigies in ipsa Lateranensi basilica, ubi primus idem Magnus Constantinus Augustus sacri baptismi lavacro emundatus est, simul reperiri voluerit, quae summam eorum erga invictissimam crucem pietatem et eximiam religionem aperte palamque profiterentur.

2. Theodosii igitur senioris imperatoris religiosissimi memoria in benedictione sit, qui se Nicaenae Fidei defensorem acerrimum praestitit, qui lege edita, eam se tantum fidem sequi, quam a beatissimo apostolo Petro Romanis traditam Damasus Pontifex docebat, apud cunctos populos publice testificatus est; qui in ecclesiae cultu ac veneratione disciplinam imitatione dignam, non solum legibus edictisque professus est, sed etiam mirifice coluit; qui denique, ob gravem Thessalonicensium caedem a sancto Ambrosio episcopo publice correptus, et ab ingressu ecclesiae repulsus, insigni christianae humilitatis exemplo reverenter abstinuit, et impositam ab eodem Ambrosio poenitentiam humiliter suscepit, libentique animo adimplevit, quo obedientiae et poenitentiae exemplo is, qui claustra imperii Christi Domini sic validis praesidiis ante munierat, non solum reipublicae hostes submovit, verum etiam christiani nominis gloriam feliciter adauxit.

3. Sed et duorum filiorum eius Arcadii et Honorii nomen cum benedictione meminisse libet, qui pietatis ac disciplinae praeceptis institutisque a S. Arsenio Romanae Ecclesiae diacono instructi, ut christianam religionem propagarent, ubique terrarum simulacra idolorum confringi, eorumque templa dirui, legibus sanxerunt, catholicae porro fidei integritatem constantissime retinentes, haereticos omnes imperii viribus coercuerunt, quod communes ab eis promulgatae leges adhuc ostendunt.

Illud autem proprium Honorio occidentale imperium regenti, quod basilicam Sancti Pauli, a Valentiniano iuniore amplificari coeptam, omnibus partibus absolvi atque exornari curavit ; quodque beato Augustino, firmissimae Ecclesiae columnae, in comprimendis et propulsandis Africanis haereticis magno adiumento fuit.

Id quoque laudi potissimum Arcadio tribuitur, quod cum eius militibus contra Persas bene pugnantibus cruces aureae in vestibus apparuissent, ut victoriae divinitus partae monumentum ubique extaret, is auream monetam cum eodem crucis signo fieri voluit. 
4. Atque Theodosio quidem iuniore, Arcadii filio, in oriente, et Valentiniano tertio, eorumdem Arcadii et Honorii sororis filio, in occidente imperii gubernacula tenentibus, sancta tertia universalis Ephesina Synodus contra impium Nestorium, ex beatissimi Coelestini Romani Pontificis auctoritate, indicta et celebrata est ; quo tempore amborum imperatorum pietas in fovenda tuendaque eadem Sinodo, et Ecclesiae pace per sanctorum Patrum definitionem procuranda, magnopere eluxit.

Valentinianus autem, beatae memoriae Sixti III Pontificis hortatu, ipsius basilicae Lateranensis fastigium argenteum a barbaris ereptum, magna in id opus erogata pecunia, refecit, ac Sancti Leonis Pontificis cultor eximius, uberrimum suae pietatis fructum tulit, cum eius etiam precibus, idem beatissimus Pontifex, immanissimum Attilam, Flagellum Dei vocatum, divina sua eloquentia atque auctoritate placavit ac deterruit, horribilemque tempestatem iam imminentem ab ipsa Roma atque a tota Italia avertit.

5. Marcianus vero, simul atque ad imperium evectus est, ad eumdem Sanctissimum Pontificem Leonem litteras dedit pietatis et erga Apostolicam Sedem observantiae plenas. Quare, apostolica auctoritate et catholici imperatoris adiumento, magnum illud sexcentorum triginta episcoporum Chalcedonense concilium adversus Eutychen et Dioscorum coactum est, in quo Marcianus ipse insigni elogio novus Constantinus est appellatus.

6. At Leo Caesar, Dei spiritu et crebris Sancti Leonis Papae epistolis roboratus, nullis se haereticorum machinis passus est a catholicae fidei constantia et Chalcedonensis Synodi propugnatione dimoveri.

7. Nec vero praetereundus nobis est vere pius et catholicus imperator senior Iustinus, qui sanctum Germanum Capuanum episcopum, Sanctissimi Hormisdae Papae legatum, tamquam angelum Domini, summo cum honore excepit, cuius imperatoris pietas hoc quoque promeruit, ut et beatum Ioannem Summum Pontificem Constantinopolim ad se venientem videret, admirabili sanctitate virum et postea martyrii gloria illustrem, ad cuius ille pedes, Christum in eo agnoscens, procubuit, Deo clarissimum illum congressum insigni miraculo comprobante, cum in ipso aditu Portae Aureae, coeco supplicanti ab eodem Summo Pontifice lumen est restitutum.

8. Magnis etiam laudibus efferendus est Iustinianus ille, qui tot rebus fortiter sapienterque gestis, magnus merito est appellatus, sed profecto sui ipsius victoria et erga Apostolicam Sedem obedientia multo maior. Nam cum zelo catholicae religionis confessionem verae ac othodoxae fidei quae in sancta Dei Ecclesia praedicatur, et simul haeresum damnationem, de catholicorum episcoporum consensu, proposito edicto, fecisset omnibus manifestam, ac deinde per suas litteras et legatos, reddens Apostolicae Sedi et S. Ioanni Papae II debitum honorem et reverentiam, pro singulari studio quo gerebat de unitate omnium, praesertim orientalis tractus ecclesiarum, illarumque sacerdotum, cum ipso ac eius sede, tamquam earum capite, servanda atque custodienda, etiam suae fidei confessionem ac illud ips um edictum transmisisset, humiliterque postulasset suis illa litteris et Apostolicae Sedis iudicio comprobari atque ipsis quoque 
diebus B. Petro Principi apostolorum pretiosa munera obtulisset, idem Sanctus Pontifex, et dignis eum laudum praeconiis extulit, et quae in ipso edicto continebantur, veluti apostolicae doctrinae consentanea, suo iudicio atque auctoritate confirmavit. Cumque postmodum ipse Iustinianus imperator, a Theodora coniuge depravatus, a beato Agapito Pontifice vehementius contenderet ut Anthymum haereticum patriarcham ad communionem admitteret, eiusque electionem confirmaret, eoque constantissime recusante, minas precibus admisceret, Sanctus Pontifex zelo fidei incensus, exclamavit: Ego ad Iustinianum Imperatorem christianissimum venire desideravi, sed Diocletianum iuveni ; qua invicti animi constantia permotus imperator, ac tandem erroris caligine detersa, ad veritatis lucem emergens, seipsum totum ad parentis in Christo optimi voluntatem conformavit, hominemque haereticum loco deiici, et catholicum episcopum Mennam ab eodem Sancto Pontifice consecrari non solum patienter, sed etiam libenter tulit, praeclaro christianis principibus exemplo relicto ut paternas Christi Vicarii admonitiones et obiurgationes aequissimo animo ferrent, memores verbi Domini : Qui vos audit, me audit et qui vos spernit, me spernit.

9. Iam vero Tyberii Constantini nomen cum laude commemorandum est, quem urbis Romae conservatorem appellare licet, quod eam a Longobardis gravissima obsidione oppressam, magnaque rei frumentariae angustia laborantem, larga frumenti copia ex Aegypto transmissa, a famis simul et obsidionis calamitate, paternis sanctae memoriae Benedicti I Summi Pontificis cohortationibus, liberaverit. Hic cum Sanctum Gregorium Magnum adhuc diaconum disputantem audisset, Eutychii patriarchae, veram tractabilemque corporum resurrectionem negantis, librum statim comburendum in ignem iniecit. Idem sanctae crucis signum ita coluit, ut aliquando, cum humi eam in lapide sculptam vidisset, statim tolli et decenti loco collocari iusserit, ut iam minus mirandum sit quod magnus crucis cultor, crucis imaginem in aureis nummis eleganter, ut videmus, curaverit exprimendam.

10. Commemorandus est etiam iure optimo Mauritius vir fortissimus, cuius filium idem Gregorius, cum adhuc diaconus Constantinopoli apostolicum legatum ageret, ex sacro Baptismi fonte levavit ; postea vero Pontifex factus, eidem Mauritio locupletissimum pietatis testimonium praebet, dum illum in suis epistolis hominem multarum lacrymarum, orationum, ieiuniorum et elaemosynarum fuisse commemorat. Certe de Apostolica Sede et universa Italia egregie est meritus, quod exercitu comparato, ducibus in Italiam missis, Francorum auxiliis advocatis, omni denique diligentia adhibita, Longobardorum furorem non mediocriter represserit.

11. Nec minori dignus est praeconi Phocas imperator, qui cum de more conaretur, se catholicae religionis defensorem perpetuum futurum sanctissimo iureiurando obstrinxit, et summam ab ipso Christo Domino Romanae Ecclesiae traditam auctoritatem et potestatem praeclare intelligens, publice edixit ut eamdem sanctam Romanam Ecclesiam, tamquam omnium Ecclesiarum primam atque caput, omnes et agnoscerent et profiterentur. 
12. Hunc autem clarissumum coetum merito claudit Eraclius augustus, novissumus eorum quos supra enumeravimus, qui sacrosanctam crucem illam ipsam, in qua vitae auctor pependerat et mortem moriendo superaverat, decimoquarto anno, postquam venerat in potestatem Persarum, felicissime recepit, eamque suis humeris, abiecto imperatorio amictu, calceisque detractis, in ipsum Calvariae montem, in passionis Christi memoriam, magna cum humilitate reportavit.

13. Nos igitur, aliquam augustissimae eorundem imperatorum memoriae gratiam non immerito referre cupientes, carissimis in Christo filiis nostris Romanorum imperatori electo, ac regibus et dilectis filiis nobilibus viris principibus, quos in visceribus Christi gerimus, quaedam ex supradictis aureis numismatibus, singulare paterni nostri amoris erga ipsos pignus, misimus, ut ad similem virtutis et religionis laudem excitentur, et se Ecclesiae Romanae filios, catholicorum principum successores et crucis Christi defensores esse crebius reminiscantur, veteres in hoc quidem sanctos Pontifices praedecessores nostros, praesertim eumdem Beatum Gregorium Papam, imitati, qui regibus et principibus ac primariis viris aureas cruces et claves parvulas, quae claves B. Petri dicebantur, mittere consueverant, quaeque, collo appensae et religiose gestatae, miraculis coruscabant; quaedam vero alia ex eisdem numismatibus dedimus venerabilibus fratribus nostris S. R. E. cardinalibus, reliqua vero eodem modo piis et praestantibus viris iam distribuimus.

14. Ut autem ab omnibus et singulis Christi fidelibus, quibus a nobis tradita iam sunt, devotius ac religiosius et cum spirituali animarum fructu gestentur, decrevimus, ad sanctissimae crucis honorem et gloriosam memoriam imperatorum, eadem numismata praecipuis gratiis et indulgentiis amplissimis ex nostra apostolica benignitate insignire.

15. Quamobrem de omnipotentis Dei misericordia ac beatorum apostolorum eius Petri et Pauli auctoritate confisi, universis et singulis Christi fidelibus utriusque sexus, quodcumque ex his numismatibus penes se gestantibus, quoties eorum aliquis ante salutiferae crucis signum aut sacram aliquam imaginem pertransiens, operto capite, venerationem tribuerit aut genuflexerit, Orationem Dominicam vel Salutationem Angelicam pronunciando, toties ei centum annos et totidem quadragenas.

Singulis autem diebus, si ter Orationem Dominicam Salutationemque Angelicam, aut semel Psalmum Miserere mei Deus seu De profundis clamavi devote recitaverit, annos ducentos, ac etiam totidem quadragenas.

Item quoties ad Deum mentem elevaverit, illiusque divinam opem imploraverit, etiam ducentos annos et totidem quadragenas.

Si vero quocumque dominico aut festo die coronam Beatissimae semper Virginis Dei genitricis Mariae etiam pia devotione recitaverit, annos trecentos et totidem quadragenas.

Ac si conscientiam suam mane aut vesperi, cum emendationis proposito, examinaverit, ac de male anteacta vita veniam supplex a Deo misericordiarum patre postulaverit, similiter trecentos annos et totidem quadragenas de sibi iniunctis vel alias quomodolibet per eum debitis poenitentiis, misericorditer in Domino relaxamus. 
Atque ut eosdem fideles ad pietatis opera exercenda eo etiam magis invitemus, eorum cuilibet, quoties pro haereticorum reductione, infidelium conversione, christianae atque orthodoxae fidei propagatione, et sanctae matris Ecclesiae tranquillitate et exaltatione, ac inter principes christianos pace et concordia, Deum precando, Orationem Dominicam Salutationemque Angelicam quinquies devote dixerint, easdem illas indulgentias ac peccatorum remissiones, quae unam e septem praecipuis Urbis basilicis visitantibus concessae sunt, concedimus et impartimur.

Quod si quis peccatorem a via perditionis, veluti ab haeresi, blasphemia alliisve eiusmodi sceleribus et peccatis, ad viam salutis converterit, aut si certe in eo laboraverit, aut si inter discordantes pacem conciliaverit, aut quantum in se est, procuraverit, concedimus ut sanctorum sacrificiorum, ieiuniorum, orationum ac quorumvis aliorum priorum operum, quae in omnibus Ordinibus et congregationibus regularibus sanctae catholicae Ecclesiae fiunt, non secus ac si uniuscuiusque earum proprium membrum foret, eo ipso particeps efficiatur.

Praeterea unicuique vere poenitenti, qui peccata sua alicui ex sacerdotibus idoneis et ad id approbatis confessus fuerit, et sacram sumpserit Eucharistiam aut missam, si sacerdos fuerit, celebraverit, quoties id fecerit, toties ei plenariam.

Aut si in mortis articulo constitutus, numisma collo appensum aut quovis modo secum habuerit, pronunciato nomine Iesu, corde saltem, si ore nequiverit, etiam plenariam.

Atque itidem militibus aut aliis qui aliquod huiusmodi numisma secum habentes contra infideles vel haereticos aut alios S. R. E. hostes pugnaverint, praesertimque si ibi eos mori contigerit, Iesu nomine, ut supra, invocato, pariter plenariam omnium peccatorum suorum indulgentiam et remissionem, auctoritate praedicta, tenore praesentium, etiam misericorditer in Domino concedimus et elargimur.

Utque defectus et negligentiae animique distractiones, quae ex humana fragilitate in Divini officii recitatione, missarumque celebratione vel auditione sacerdotibus aut clericis vel laicis contingere solent, aut horum etiam ob iustum impedimentum praetermissio, ex devota huius numismatis gestatione, corona tamen Beatae Mariae Virginis pie recitata, aut saltem pronunciato psalmo Miserere mei Deus, suppleri et compensari possint, eadem auctoritate concedimus et indulgemus.

16. Quicumque autem aliquod huiusmodi numisma habuerit ipsum pro suo arbitrio in testamento aut alia ultima voluntate cui voluerit ecclesiae, nec vero cuiquam alii, absque speciali nostra aut nostrorum successorum concessione, relinquere aut donare possit.

17. Quam quidem ecclesiam, in qua fuerit dictum numisma repositum, festis diebus Inventionis et Exaltationis Sanctae Crucis, universis et singulis Christi fidelibus utriusque sexus vere poenitentibus et peccata sua confessis, devote visitantibus, similiter plenariam omnium peccatorum suorum indulgentiam et remissionem damus, concedimus et elargimur. 
18. Quod si quis numisma habens ab intestato decesserit, volumus ut illud ad propinquiorem eius domicilio ecclesiam, cum eisdem gratiis, facultatibus et indulgentiis, pertineat.

19. Cuicumque nihilominus in articulo mortis constituto, de consilio eius confessarii, ipsum numisma liceat commodare, qui itidem omnes supradictas indulgentias et peccatorum remissiones valeat obtinere.

20. Postremo ut animabus quoque Christi fidelium in purgatorio existentibus, quae per caritatem Domino nostro Iesu Christo unitae ex hac vita migraverint, quaeque antequam decederent aliorum Christi fidelium suffragiis iuvari meruerunt, de coelestibus ecclesiae thesauris, quorum dispensatores a Domino ad animarum salutem constituti sumus, paterne subveniamus, divina miseratione confisi, concedimus ut quoties quilibet aliquod ex huiusmodi numismatibus secum habens, pro dictarum animarum salute, praemissa eorumve aliqua adimplerit, vel quicumque alius ecclesias, in quibus eadem numismata exponi contigerit, dictis festis diebus Inventionis et Exaltationis Sanctae Crucis visitaverit, efficacissimis Iesu Christi Domini nostri meritis, ac eiusdem Beatae Mariae semper Virginis, sanctorum angelorum, apostolorum, martyrum, confessorum, virginum omniumque sanctorum et sanctarum precibus et intercessionibus suffragantibus, easdem indulgentias et peccatorum remissiones consequantur.

21. Praesentes vero litteras, sub quibusvis similium vel dissimilium indulgentiarum et gratiarum revocationibus, suspensionibus, abrogationibus aut aliis contrariis dispositionibus, per nos vel successores nostros Romanos Pontifices, etiam motu proprio et ex certa scientia, ac in favorem Cruciatae Sanctae vel alias quomodolibet faciendis, minime comprehendi, sed quoties illas emanabunt, toties easdem praesentes ab illis exceptas, et nisi de eis expressa et individua mentio fiat, adversus illas in pristinum et validissimum statum restitutas, ac de novo concessas esse et censeri, et perpetuo validas et efficaces fore, ac supradictis personis et ecclesiis perpetuis futuris temporibus suffragari debere decernimus et declaramus.

22. Non obstantibus nostra de non concedendis indulgentiis ad instar, ac aliis constitutionibus et ordinationibus apostolicis ceterisque contrariis quibuscumque.

23. Volumus autem ut praesentium litterarum exemplis, etc.

Datum Romae apud Sanctum Petrum, anno Incarnationis dominicae milesimo quingentesimo octuagesimo septimo, kalendis decembris, pontificatus nostri anno III.

Dat. Die 1 decemb. 1587, pontif. anno III. 
